\title{
A Functional Magnetic Resonance Imaging Study of Working Memory in Youth after Sports-Related Concussion: Is It Still Working?
}

\author{
Michelle L. Keightley, ${ }^{1-5 *}$ Rajeet Singh Saluja, ${ }^{6 *}$ Jen-Kai Chen, ${ }^{1,6}$ Isabelle Gagnon, ${ }^{7}$ \\ Gabriel Leonard, ${ }^{6}$ Michael Petrides, ${ }^{6}$ and Alain Ptito ${ }^{6,8}$
}

\begin{abstract}
In children, the importance of detecting deficits after mild traumatic brain injury (mTBI) or concussion has grown with the increasing popularity of leisure physical activities and contact sports. Whereas most postconcussive symptoms (PCS) are similar for children and adults, the breadth of consequences to children remains largely unknown. To investigate the effect of mTBI on brain function, we compared working memory performance and related brain activity using blood-oxygenlevel-dependent (BOLD) functional magnetic resonance imaging (fMRI) in 15 concussed youths and 15 healthy agematched control subjects. Neuropsychological tests, self-perceived PCS, and levels of anxiety and depression were also assessed. Our results showed that, behaviorally, concussed youths had significantly worse performances on the working memory tasks, as well as on the Rey figure delayed recall and verbal fluency. fMRI results revealed that, compared to healthy children, concussed youths had significantly reduced task-related activity in bilateral dorsolateral prefrontal cortex, left premotor cortex, supplementary motor area, and left superior parietal lobule during performance of verbal and nonverbal working memory tasks. Additionally, concussed youths also showed less activation than healthy controls in the dorsal anterior cingulate cortex, left thalamus, and left caudate nucleus during the nonverbal task. Regression analysis indicated that BOLD signal changes in bilateral dorsolateral prefrontal cortex were significantly correlated with performance such that greater activities in these regions, relative to the control condition, were associated with greater accuracy. Our findings confirmed functional alterations in brain activity after concussion in youths, a result similar to that observed in adults. However, significant differences were noted. In particular, the observation of reduced working memory accuracy suggests that youths may be unable to engage compensatory strategies to maintain cognitive performance after mTBI. This has significant implications for safe return to daily activities, including competitive sport.
\end{abstract}

Key words: concussion; fMRI; working memory; youth

\section{Introduction}

$\mathbf{O}$

NE OF THE MOST COMMONLY REPORTED INJURIES in children who participate in sports is concussion or mild traumatic brain injury (mTBI). For the purposes of this article, these two terms will be used interchangeably. Children and youth involved in organized sports are nearly six times more likely to suffer a severe concussion than those involved in other leisure physical activities. ${ }^{1}$ Whereas the most common cognitive sequelae of mTBI appear similar for children and adults, the recovery profile and breadth of consequences in children remain largely unknown. ${ }^{2}$ This dearth of literature is compounded by the recent scrutiny youth participation in competitive contact sports (e.g., hockey and football) has received.

Concussion is defined as "a complex pathophysiological process affecting the brain, induced by traumatic biomechanical forces" that may or may not involve loss of consciousness. ${ }^{3}$ Concussion is a

\footnotetext{
${ }^{1}$ Bloorview Research Institute, Holland Bloorview Kids Rehabilitation Hospital, Toronto, Ontario, Canada.

${ }^{2}$ Department of Occupational Science and Occupational Therapy, ${ }^{3}$ Graduate Department of Rehabilitation Science, and ${ }^{4}$ Department of Psychology, University of Toronto, Toronto, Ontario, Canada.

${ }^{5}$ Toronto Rehabilitation Institute, Toronto, Ontario, Canada.

${ }^{6}$ Montreal Neurological Institute, McGill University, Montreal, Quebec, Canada.

${ }^{7}$ The Montreal Children's Hospital, McGill University Health Center, Montreal, Quebec, Canada.

${ }^{8}$ Department of Psychology, McGill University Health Center, Montreal, Quebec, Canada.

*The first two authors contributed equally.
} 
concern in contact sports, such as hockey and football, because, once cleared to play after the resolution of symptoms, the players return to an environment in which a brain injury has a reasonable likelihood of recurring. The variability of the developmental impact of concussion in youths appears to result from the complex interplay between age at time of injury, its severity, and the mechanism of injury. ${ }^{4}$

Children's brain injuries were traditionally thought to be offset by physiological and adaptive factors, such as the young brain's plasticity or "reserve," which served to increase impact tolerance and recovery after insult. ${ }^{1,5,6}$ A growing amount of literature, however, strongly indicates that the immature brain is, in fact, more vulnerable, not more "plastic," to diffuse injury. ${ }^{2,6}$ Specific underlying neural mechanisms make the developing brain more vulnerable to neuronal injury, possibly because pathophysiological differences exist. These include the mechanical and compositional properties of the brain, such as brain water content, level of myelination, skull geometry, suture elasticity, and neck strength, which may result in a markedly diminished shear resistance of the immature brain tissue. ${ }^{7}$ Consequently, similar mechanical load as that applied to the mature brain could, in fact, induce more-intense brain tissue displacements. A concussion sustained before or during critical developmental periods may permanently alter and impair the development of a particular function or skill, such as working memory (the ability to temporarily store and manipulate information for the purpose of carrying out a complex cognitive task). ${ }^{8,9}$

Although it has been suggested that individuals with mTBI typically recover within 1-2 weeks, ${ }^{10,11}$ symptoms and related performance deficits persisting for several weeks to months postinjury have been reported in a small, but significant, number of youths. ${ }^{12}$ Most recently, Baillargeon and colleagues ${ }^{13}$ reported that adolescents are more susceptible to short-term neuropsychological and -physiological deficits after concussion than younger children and adults.

Relatively recent advances in magnetic resonance imaging (MRI) technology have enhanced its sensitivity to detect traumatic abnormalities among concussed athletes, including the characterization of diffuse axonal injury, defined as foci of abnormal signal intensity. ${ }^{14-17}$ Whereas MRI can furnish knowledge of structural anatomical abnormalities, functional techniques, such as functional MRI (fMRI), reveal the pathophysiological and functional sequelae of injury.

Although working memory performance in adults has been found to be comparable to healthy controls after concussion, notable differences in brain activation patterns accompanying task performance have been observed and include both increased and decreased activations, relative to control subjects, across frontal, parietal, and temporal areas, with increased activity found in regions not typically employed during working memory (i.e., temporal cortices). ${ }^{18-23}$ Together, these results suggest that recruitment of other brain regions in adults may represent cerebral compensatory mechanisms to maintain cognitive performance.

Despite the availability of research findings in adult athletes, research utilizing neuroimaging approaches, such as fMRI, to investigate the neural impact of concussion have largely neglected the pediatric population. ${ }^{24}$ This represents a critical oversight because findings from adult data cannot be applied to this population. Developmentally, brain changes in healthy children and youth on working memory tasks involve increased localization in regions associated with increased age, such as the dorsolateral prefrontal and parietal cortices. ${ }^{25-27}$

A recent scoping review identified only five studies investigating the neural impact of pediatric concussion (19 years of age or younger), as measured with structural and functional MRI techniques. ${ }^{24}$ Only two of these studies were focused specifically on sports-related concussion and presented fMRI data. ${ }^{28,29}$

Specifically, Yang and colleagues ${ }^{30}$ found hypoactivation during an auditory orienting task in mTBI youth, relative to healthy controls, but this difference did not correlate with task performance and there were no statistically significant differences between the groups. However, because moderate effect sizes and trends for group differences in performance were found, the researchers argued that the lack of group differences may be a result of the small sample size. Talavage and colleagues ${ }^{28}$ also recorded functional changes in brain activity associated with a working memory n-back task from pre- to in-season assessment in football players with clinically diagnosed concussion, as well as in a subset of players who sustained a high number of high-magnitude impacts, but who did not present with clinically identified concussion. Specifically, fMRI activation patterns shifted from greater activity during the more-complex task to greater activity during the less-complex task, suggesting hyperactivation associated with the simpler task condition. However, the researchers did not report whether there were performance differences between groups on the tasks. Hyperactivation in the frontal and parietal lobes on a working memory task has also been found to predict length of time to recovery in concussed high school athletes, with the mean age of participants being approximately 18 years (range, 13-24). ${ }^{31}$ Taken together, the paucity of literature in adolescent athletes indicates that more research is needed to better understand the clinical and neural implications of concussion in youth.

Thus, the aim of the present study was to examine and compare working memory performance and related brain activity using fMRI in concussed youths and healthy age-matched control subjects. We employed the same working memory task previously described by Chen and colleagues ${ }^{20,21}$ in concussed adult athletes. Because decreased working memory performance has been observed in children and youths after mTBI, ${ }^{32,33}$ we hypothesized that, unlike studies involving adult participants, concussed youths would demonstrate observable differences in working memory performance, compared to age-matched healthy controls. Further, we hypothesized that deficits in performance would be linked to reduced change in activation from baseline to task performance. This reduced change in activation is hypothesized to occur primarily in the dorsolateral prefrontal cortex and brain areas previously shown to be preferentially involved during working memory in both children and adults. ${ }^{20,21,23,31,34,35}$

\section{Methods \\ Participants}

Participants included 15 concussed youths ( 8 females and 7 males; mean age, $14.47 \pm 2.29$ years) who had previously sustained a concussion ranging from 9 to 90 days at the time of testing, as well as 15 age-matched control subjects ( 7 females and 8 males; mean age, $14 \pm 2.3$ years). Inclusion criteria for the mTBI groups were: 1 ) a diagnosis of mTBI, as per the World Health Organization task force definition, ${ }^{36}$ by a physician at the Montreal Children's Hospital (Montreal, Quebec, Canada), where the children were recruited. Operational criteria for clinical identification included the following: i) confusion or disorientation, loss of consciousness (LOC) for $30 \mathrm{~min}$ or less, post-traumatic amnesia for less than $24 \mathrm{~h}$, and/or transient neurological abnormalities, such as focal signs, seizure, and intracranial lesion not requiring surgery; ii) Glasgow Coma Score of 13-15 after 30 min postinjury or later upon presentation for health care; 2) no history of mTBI at least in the 
previous year; and 3) a functional knowledge of French or English. Exclusion criteria included a premorbid diagnosis of learning disabilities, attention deficit hyperactivity disordered (ADHD), and/or behavior problems. Because many children present with features of ADHD without having been formally diagnosed, parents filled out the Conners' Rating Scale $(\mathrm{CRS})^{37}$ while their child underwent testing. This scale provides additional information for screening for attention, learning, and behavioral problems. Based on cut-off scores provided in the literature, we excluded those children who displayed 1) severe clinical criteria for ADHD (90th percentile on all scales), 2) severe pain and vestibular, neurological (other than mTBI), or musculoskeletal problems (other than upper extremity injuries), and 3) violation of standard criteria regarding eligibility for MRI scan. All participants were right-handed and screened to ensure that there was no history of psychological or neurological illness apart from the current concussion. Of the 15 concussed subjects, 3 had a history of a previous concussion more than 1 year earlier. All control subjects were given the same screening questionnaire as the concussed subjects to ensure that they had no major medical issues, no history of any pre- or perinatal insults, learning disabilities, history of ADHD, neurological or psychiatric conditions, history of any oncologic conditions, nor any history of recurrent ear infections. In addition, the control subjects also reported an absence of any previous concussions.

Data regarding age, gender, presence or absence of LOC, time since injury, and degree of postconcussion symptoms (PCS) present at the time of testing are presented in Table 1. Structural scans for mTBI subjects were reviewed by a neuroradiologist who was blind to their injury status. All were reported as normal. PCS were assessed using an adapted version of the Post-Concussion ScaleRevised. ${ }^{38}$ The scale consists of 21 symptoms (i.e., headache, nausea, dizziness, and so on) assessed by the subject on a scale from zero to six, with six being a severe problem. Total PCS scores reflect the following severities: $0-5=$ within normal limits; $6-$ 21 low PCS; $22-84=$ moderate PCS; and 85-132= high PCS. ${ }^{20,21}$ Each participant provided informed written consent as approved by the ethics committee at McGill University, Montreal Neurological Institute (Montreal, Quebec, Canada).

\section{Neuropsychological testing}

All participants completed a comprehensive neuropsychological battery, comprised of tests that demonstrate the greatest sensitivity to the effects of mTBI. Tests administered included the Wechsler Abbreviated Scale of Intelligence (WASI), ${ }^{39}$ Rey Complex Figure, ${ }^{40}$ Verbal Fluency, ${ }^{41}$ Rey Auditory Verbal Learning Test (RAVLT) ${ }^{42}$ Stroop Color and Word Test, ${ }^{43}$ Symbol Digit Modality Test (SDMT), ${ }^{44}$ Children's Color Trails Test, ${ }^{45}$ and the Place and Remove tasks of the Grooved Pegboard Test. ${ }^{46}$ We also assessed behavior and emotional functioning by obtaining parent reports on the $\mathrm{CRS}^{37}$ and the Child Behavior Checklist (CBCL). ${ }^{47}$ The CRSRevised (CRS-R) evaluate problem behaviors by obtaining reports from a child's parents and teachers across a number of domains (i.e., oppositional behavior, inattention, hyperactivity, and so on). The CBCL is a series of parent/teacher/self-report questionnaires designed to assess competencies, adaptive functioning, and problems

Table 1. Demographic, Medical, and Injury Information for All Participants

\begin{tabular}{|c|c|c|c|c|c|c|c|}
\hline Subject ID & Group & Gender & $\begin{array}{c}\text { Age } \\
\text { (years) }\end{array}$ & $\begin{array}{l}\text { Time since } \\
\text { injury (days) }\end{array}$ & Mechanism of injury & $P C S$ & $\begin{array}{c}\text { Number of previous } \\
\text { concussions }\end{array}$ \\
\hline ТC079 & mTBI & $\mathrm{F}$ & 10 & 41 & Hit wall in gym class & 2 & 0 \\
\hline TC051 & mTBI & M & 11 & 61 & Kicked in head playing soccer & 14 & 0 \\
\hline TC033 & mTBI & M & 12 & 90 & Fell playing soccer & 17 & 0 \\
\hline TC078 & mTBI & $\mathrm{F}$ & 13 & 12 & Fell playing ringette & 62 & 0 \\
\hline TC050 & mTBI & M & 13 & 34 & Hit head while swimming & 32 & 0 \\
\hline TC068 & mTBI & $\mathrm{F}$ & 14 & 49 & Hit head playing football & 39 & 0 \\
\hline TC056 & mTBI & $\mathrm{F}$ & 14 & 62 & Hit head against wall while swimming & 47 & 0 \\
\hline TC007 & mTBI & $\mathrm{F}$ & 15 & 16 & Hit in head by ball in soccer & 45 & 1 \\
\hline TC074 & mTBI & $\mathrm{F}$ & 15 & 20 & Fell playing ringette & 12 & 0 \\
\hline TC053 & mTBI & M & 15 & 19 & Struck on head by a knee while on trampoline & 35 & 0 \\
\hline TC069 & mTBI & $\mathrm{F}$ & 17 & 72 & Hit in head by ball playing soccer & 29 & 0 \\
\hline TC001 & mTBI & M & 17 & 26 & Fell while skiing & 39 & 0 \\
\hline TC076 & mTBI & M & 17 & 9 & Hit head playing football & 54 & 1 \\
\hline TC077 & mTBI & $\mathrm{F}$ & 17 & 44 & Hit head playing soccer & 33 & 0 \\
\hline TC067 & mTBI & M & 17 & 62 & Hit head playing football & 0 & 1 \\
\hline TC009 & Control & $\mathrm{F}$ & 10 & & N/A & 2 & 0 \\
\hline TC003 & Control & M & 11 & & & 10 & 0 \\
\hline TC022 & Control & M & 12 & & & 3 & 0 \\
\hline TC045 & Control & $\mathrm{F}$ & 13 & & & 33 & 0 \\
\hline TC021 & Control & M & 13 & & & 15 & 0 \\
\hline TC004 & Control & $\mathrm{F}$ & 14 & & & 20 & 0 \\
\hline TC055 & Control & M & 14 & & & 9 & 0 \\
\hline TC011 & Control & $\mathrm{F}$ & 15 & & & 13 & 0 \\
\hline TC010 & Control & $\mathrm{F}$ & 15 & & & 7 & 0 \\
\hline ТC049 & Control & M & 15 & & & 6 & 0 \\
\hline TC041 & Control & $\mathrm{F}$ & 17 & & & 6 & 0 \\
\hline TC040 & Control & M & 17 & & & 5 & 0 \\
\hline TC036 & Control & M & 17 & & & 21 & 0 \\
\hline TC029 & Control & $\mathrm{F}$ & 17 & & & 32 & 0 \\
\hline TC037 & Control & M & 17 & & & 21 & 0 \\
\hline
\end{tabular}

PCS as assessed on the day of scanning using the Post-Concussion Symptom Scale-Revised.

mTBI, mild traumatic brain injury; F, female; M, male; PCS, post-concussion symptoms; N/A, not available. 
in child behavior that map onto the major mood and behavioral disorders listed in the Diagnostic and Statistical Manual of Mental Disorders (4th edition). Finally, participants' self-perceived levels of anxiety and depression were assessed by the Beck Youth Inventories. ${ }^{48}$ The testing was performed by a neuropsychologist blinded to the injury history of all subjects and was completed in a standardized order. All testing was completed over a period of 1.5$2.0 \mathrm{~h}$ in a single session, either before or after the MRI testing, depending on scheduling constraints.

\section{Functional magnetic resonance imaging experimental task}

The experimental task used during the fMRI session was an adapted version of the externally ordered working memory task devised by Petrides and colleagues ${ }^{49}$ and validated in studies of patients with lateral frontal lesions, monkeys with dorsolateral prefrontal cortex lesions, and functional neuroimaging work with positron emission tomography and fMRI. ${ }^{50,51}$ This task has also been used with adult concussed athletes where less activity in the dorsolateral prefrontal cortex was found during working memory performance, compared with baseline task performance. ${ }^{20,21} \mathrm{We}$ replicated the methodology (imaging protocol and working memory tasks) to compare findings from adults to concussed youth. There are two versions of the task: verbal and nonverbal (see Fig. 1). In each, subjects were familiarized with a set of five items that were to be used throughout the test (five abstract drawings or five pseudo words). On each trial, four of the five items were presented successively in random order at the center of a computer screen. The subject had to monitor their occurrence and identify the one item from the set that had not been presented. The four items presented were randomly selected from the five items. After the presentation of the fourth item, a 1-sec delay occurred. Immediately after this delay, a test item was presented and the subject had to indicate within $1.5 \mathrm{sec}$, by pressing a mouse button (yes = right button; no=left button), whether this test item was one of the four items presented before the delay or whether it was the item from the set of five that had not been presented.

A control condition was introduced to "subtract out" any activation related to the motor and perceptual components of the working memory task. In the control condition, the format and type of stimulus presentation, mode of response, and timing of events were identical to those in the experimental working memory task. The stimuli used in the control condition were similar, but not previously used for the experimental task. During stimulus presentation in each trial, a single item (abstract design or pseudo word for the nonverbal and verbal conditions, respectively) was presented four times in succession at the center of the screen, followed by a delay of $1 \mathrm{sec}$. After the delay, one of two items associated with either a left or a right mouse button press was presented at the center of the screen and the subject had $1.5 \mathrm{sec}$ to respond. The subjects learned before scanning which one of the two items (two abstract designs or two pseudo words) was associated with a left mouse button press and which one with a right button press. Thus, in the control condition, the subject was making an identical response as in the experimental task (i.e., press left or right), but these motor responses were based on particular conditional associations learned before scanning rather than a decision based on the monitoring of information in working memory (i.e., whether a particular item from the expected set of five had or had not been presented during the trial). Thus, the crucial difference between the experimental and control conditions was that the working memory task required constant monitoring of which items from a familiar set of stimuli had or had not been presented (i.e., an executive function depending on the dorsolateral prefrontal cortex), whereas in the control task, the decision was made on the basis of learned associations. The experimental task was administered by two trained examiners. A graphical illustration of the task can be found in Figure 1.

\section{Image acquisition}

The fMRI scanning was carried out using a 3T Siemens MAGNETOM Trio ${ }^{\mathrm{TM}}$ A Tim System with a 32-channel head coil (Siemens Medical Solutions, Erlangen, Germany). Each fMRI session started with the acquisition of high-resolution T1-weighted three-dimensional (3D) anatomical images using 3D magnetization prepared rapid gradient echo sequence (time of repetition $[\mathrm{TR}]=23 \mathrm{~ms}$; echo time $[\mathrm{TE}]=2.98 \mathrm{~ms}$; slice thickness $=1 \mathrm{~mm}$; image matrix $=256 \times 256$; flip angle $=30$ degrees; field of view $[\mathrm{FOV}]=256 \mathrm{~mm}$; interleaved excitation), followed by acquisitions of $\mathrm{T} 2 *$-weighted gradient echo (GE) echo-planar images (EPIs) for blood-oxygenation-level-dependent $(\mathrm{BOLD}) \mathrm{fMRI}(\mathrm{TR}=3000 \mathrm{~ms} ; \mathrm{TE}=51 \mathrm{~ms}$; flip angle $=90$ degrees; in-plane resolution $=2.34 \times 2.34 \mathrm{~mm}$; FOV $=300 \mathrm{~mm} ; 128 \times 128 \mathrm{im}-$ age matrix; slice thickness $=4 \mathrm{~mm}$; number of slices: 37 ; interleaved excitation).

Four functional scans (two for the verbal working memory condition and its control and two for the nonverbal working memory condition and its control) were acquired in a single session. Each functional scan lasted $6 \mathrm{~min}$, with activation and

\section{Working Memory Condition}

\section{Baseline Task Condition}

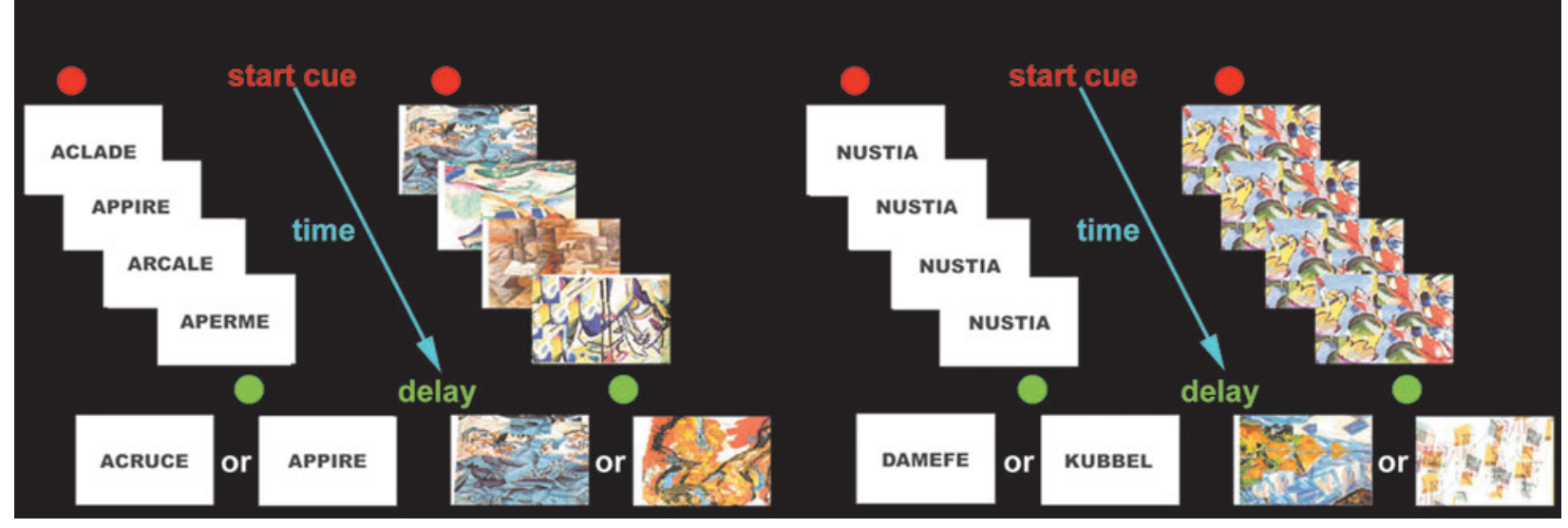

FIG. 1. Schematic diagram of the externally ordered working memory task. Color image is available at www.liebertpub.com/neu 
baseline conditions alternating every eight trials $(60 \mathrm{sec})$. Before entering the scanner, all participants were introduced to the tasks and given at least 48 practice trials (i.e., two runs) outside the scanner before entering the magnet.

\section{Statistical analyses}

All behavior data analyses were conducted using the IBM Statistical Package for the Social Sciences (version 19.0 for Windows; IBM Corp., Armonk, NY).

\section{Post-Concussion Symptom Scale-Revised}

A total score for participants' endorsement of PCS was generated by summing the ratings for each of the 21 symptoms. Graphing revealed that the data were positively skewed, so a nonparametric test (Mann-Whitney's U) was performed to compare degree of perceived symptoms for mTBI versus control subjects. Spearman's correlations were carried out to determine whether performance on the fMRI experimental task was significantly correlated with participants' degree of endorsement of PCS.

\section{Neuropsychological testing and parental questionnaires}

The statistical analyses performed on the neuropsychological testing data included descriptive statistics calculated by group. For all tests, Student's $t$-tests were performed to determine whether any group differences existed using an $\alpha$ of 0.01 given the multiple comparisons performed. For tests consisting of multiple-component measures (i.e., RAVLT), multivariate analysis of variance (MANOVA) was performed using the group (concussed vs. control) as the independent variable and each of the submeasures (i.e., immediate memory recall, delayed memory recall, and so on) as the dependent variables.

\section{Functional magnetic resonance imaging experimental task data}

Descriptive statistics for the sample were calculated for the total sample and by group. A MANOVA was calculated where group (concussed vs. control) was the between-subjects variable and working memory performance measures (verbal control condition accuracy, verbal control condition reaction time [RT], verbal working memory condition accuracy, verbal working memory condition RT, nonverbal control condition accuracy, nonverbal control condition RT, nonverbal working memory condition accuracy, and nonverbal working memory condition RT) were the within-subjects variables.

\section{Functional neuroimaging data}

Whole-brain voxel-wise statistical analysis of the motion-corrected fMRI time series was performed with fMRIstat. ${ }^{52}$ The fMRI data were first converted to percentage of whole volume. Significant BOLD changes between experimental (i.e., working memory task) and baseline (i.e., control task) conditions were determined at each voxel, based on a linear model with correlated errors $(Y=X \beta+\mathrm{e})$. A design matrix containing the explanatory variables $(X)$, and their respective onset time and duration, was first convolved with a hemodynamic response function modeled as a difference of two gamma functions and corrected for slice timing to coincide with the acquisition of each slice. ${ }^{53}$ Temporal and spatial drifts and other estimated errors (e) were modeled and removed. The linear model was then fit with the fMRI time series $(Y)$, solving parameter estimates $(\beta)$ in the least-squares sense, yielding estimates of effects, standard errors, and $t$ statistics for each run.

Data from each individual run were then normalized to the Montreal Neurological Institute template (MNI305) using an inhouse algorithm ${ }^{54}$ and combined together using a fixed-effects analysis for the following comparisons: 1) verbal working memory minus verbal control condition and 2) nonverbal working memory minus nonverbal control condition. Within-group average across participants was achieved by using a mixed-effects linear model with fixed-effects standard deviations (SDs) taken from the previous analysis. A random-effects analysis was performed by first estimating the ratio of the random-effects variance to the fixed-effects variance, then regularizing this ratio by spatial smoothing with a Gaussian filter. The variance of the effect was then estimated by the smoothed ratio multiplied by the fixed-effects variance. The amount of smoothing was chosen to achieve 100 effective degrees of freedom. The resulting $t$-statistic images were thresholded using the minimum given by a Bonferroni correction and random field theory to correct for multiple comparisons, taking into account the nonisotropic spatial correlation of the errors. ${ }^{55}$ Threshold for significance was established at $t=4.10$ for the activation peaks, or $t=3.10$ for activation clusters greater than $222 \mathrm{~mm}^{3}$, based on the number of resolution elements in the acquisition volume (2880 resels).

Finally, to address differences in brain activity between mTBI and healthy controls, a group subtraction analysis was carried out on the data for the group average analysis, using a fixed-effects model. In control minus mTBI subtraction, positive $t$ statistics showed brain regions that had greater increase in activity during working memory against control task for control group relative to the mTBI group, and vice versa for the mTBI minus control subtraction. The percent BOLD signal change, relative to the control task, was also extracted at voxels of interest obtained from this analysis, which were identified as 6-mm-radius gray matter volume centered at the voxel with the highest $t$ value from the group subtraction analysis.

To identify brain regions where performance modulated BOLD signal changes, whole-brain, voxel-wise linear regressions were carried out using performance (accuracy) as the covariate in separate analyses for each working memory condition against the respective control task condition. This analysis was completed to look for systematic variation in BOLD signal change as a function of performance and to determine whether there was a link between performance and BOLD signal change in those brain areas where the concussed group may differ from the control group.

\section{Results}

\section{Post-Concussion Symptom Scale-Revised}

Mann-Whitney's U test for independent samples revealed that the total score for the Post-Concussion Scale-Revised (PCS-R) was higher for the mTBI, compared to the control group $(p=0.011)$. Further, perceived severity of PCS was not significantly correlated with any of the fMRI experimental task performance measures.

\section{Neuropsychological testing and parental questionnaires}

Using Student's $t$-tests, of all the variables examined using an $\alpha$ of 0.01 , only the Rey figure delayed recall $(p=0.0083)$ and verbal fluency ( $p=0.0078$ ) showed a statistically significant difference between the concussed subjects and controls. In both cases, as expected, the controls performed better than the concussed subjects. Using MANOVA, none of the tests demonstrated statistically significant differences between the two groups. The results are summarized in Table 2.

\section{Functional magnetic resonance imaging experimental task data}

Table 3 depicts the means, SDs, and 95\% confidence intervals for the mTBI and control groups on the working memory and 
Table 2. Summary of Neuropsychological Testing and Parental Questionnaires

\begin{tabular}{|c|c|c|c|c|c|c|}
\hline \multirow[b]{2}{*}{ Test } & \multicolumn{2}{|c|}{ Mean } & \multicolumn{2}{|c|}{$S D$} & \multirow{2}{*}{$\begin{array}{c}\mathrm{t}-\text { test } \\
\mathrm{p} \text { value }\end{array}$} & \multirow{2}{*}{$\begin{array}{c}\text { MANOVA } \\
\text { p value }\end{array}$} \\
\hline & Control & $m T B I$ & Control & $m T B I$ & & \\
\hline \multicolumn{7}{|l|}{ WASI } \\
\hline IQ score & 115.3 & 110.5 & 13.7 & 9.2 & 0.23 & \\
\hline \multicolumn{7}{|l|}{ Rey figure } \\
\hline Copy & 30.7 & 30.4 & 3.6 & 4.0 & 0.74 & 0.81 \\
\hline Copy time & 301.7 & 325.6 & 88.8 & 139.7 & 0.47 & \\
\hline Immediate recall & 22.2 & 18.5 & 5.6 & 6.1 & 0.078 & 0.095 \\
\hline Immediate Recall time & 203.7 & 194.9 & 82.1 & 60.8 & 0.68 & \\
\hline Delayed recall & 21.0 & 17.2 & 3.9 & 4.8 & $0.0084^{*}$ & 0.072 \\
\hline Delayed recall time & 160.1 & 144.3 & 57.0 & 62.5 & 0.52 & \\
\hline Recognition & 21.4 & 20.8 & 1.4 & 2.8 & 0.51 & 0.46 \\
\hline \multicolumn{7}{|l|}{ Verbal fluency } \\
\hline Animals & 24.2 & 21.2 & 7.1 & 6.6 & 0.09 & 0.24 \\
\hline Food/drink & 23.9 & 21.9 & 8.4 & 5.4 & 0.35 & 0.45 \\
\hline $\mathrm{S}$ words & 15.7 & 11.1 & 7.1 & 3.6 & $0.0086^{*}$ & 0.031 \\
\hline F words & 13.7 & 11.4 & 6.1 & 4.2 & 0.19 & 0.25 \\
\hline Total & 77.6 & 65.6 & 24.0 & 16.3 & $0.0078^{*}$ & 0.12 \\
\hline \multicolumn{7}{|l|}{ RAVLT } \\
\hline I & 7.4 & 6.3 & 1.8 & 1.3 & 0.033 & 0.23 \\
\hline II & 9.9 & 9.8 & 2.1 & 2.1 & 0.75 & 0.96 \\
\hline III & 12.6 & 11.2 & 1.5 & 2.2 & 0.06 & 0.079 \\
\hline IV & 13.3 & 13.0 & 1.3 & 1.8 & 0.66 & 0.40 \\
\hline $\mathrm{V}$ & 13.5 & 12.9 & 1.4 & 1.7 & 0.39 & 0.21 \\
\hline $\mathrm{B}$ & 6.9 & 5.9 & 2.0 & 1.4 & 0.15 & 0.76 \\
\hline Immediate & 12.3 & 11.5 & 2.0 & 2.2 & 0.20 & 0.20 \\
\hline Delayed & 12.3 & 11.0 & 1.9 & 2.3 & 0.09 & 0.084 \\
\hline Word recognition & 14.2 & 13.7 & 1.1 & 1.7 & 0.47 & 0.57 \\
\hline \multicolumn{7}{|l|}{ Beck Youth } \\
\hline BSCI & 40.5 & 39.4 & 7.8 & 7.1 & 0.71 & \\
\hline BAI & 14.5 & 16.7 & 8.4 & 9.9 & 0.54 & \\
\hline BDI & 8.5 & 11.2 & 5.7 & 8.8 & 0.39 & \\
\hline BANI & 11.8 & 12.5 & 6.4 & 9.7 & 0.84 & \\
\hline BDBI & 6.5 & 6.3 & 4.2 & 4.4 & 0.94 & \\
\hline \multicolumn{7}{|l|}{ Stroop } \\
\hline Word Score & 92.5 & 89.1 & 32.0 & 21.4 & 0.70 & \\
\hline Color Score & 70.6 & 63.6 & 16.0 & 17.5 & 0.25 & \\
\hline Color-Word Score & 45.1 & 37.5 & 10.4 & 13.3 & 0.13 & \\
\hline Interference Score & -19.1 & -22.9 & 16.1 & 13.8 & 0.55 & \\
\hline SDMT & 61.3 & 52.2 & 13.8 & 12.8 & 0.094 & \\
\hline \multicolumn{7}{|l|}{ Color Trails } \\
\hline CT-1 Time & 14.0 & 20.8 & 4.2 & 13.4 & 0.084 & \\
\hline Standard score & 103.3 & 100.8 & 15.2 & 16.8 & 0.72 & 0.64 \\
\hline CT-2 Time & 29.3 & 37.5 & 6.3 & 13.8 & 0.099 & \\
\hline Standard score & 101.9 & 94.0 & 8.9 & 17.1 & 0.20 & 0.30 \\
\hline \multicolumn{7}{|l|}{ PASAT } \\
\hline 2.8 & 18.9 & 16.7 & 1.2 & 3.5 & 0.12 & 0.088 \\
\hline 2.4 & 16.6 & 14.7 & 1.3 & 3.9 & 0.12 & 0.18 \\
\hline 2.0 & 16.9 & 15.0 & 2.5 & 4.7 & 0.33 & 0.25 \\
\hline 1.6 & 11.8 & 11.2 & 2.5 & 2.8 & 0.54 & 0.58 \\
\hline 1.2 & 13.7 & 12.9 & 2.6 & 2.8 & 0.47 & 0.32 \\
\hline \multicolumn{7}{|l|}{ Pegboard (s) } \\
\hline Right mean & 61.0 & 60.2 & 8.5 & 10.6 & 0.82 & \\
\hline Left mean & 64.9 & 68.1 & 9.9 & 8.5 & 0.36 & \\
\hline \multicolumn{7}{|l|}{ Pegboard Removal (s) } \\
\hline Right mean & 20.5 & 23.0 & 3.0 & 9.4 & 0.30 & \\
\hline Left mean & 20.5 & 20.6 & 2.7 & 4.2 & 0.93 & \\
\hline \multicolumn{7}{|l|}{ CPRS (T-score) } \\
\hline Oppositional & 51.6 & 48.2 & 10.8 & 17.2 & 0.47 & \\
\hline Cognitive problems/inattention & 46.4 & 51.9 & 4.7 & 12.8 & 0.11 & \\
\hline
\end{tabular}


TABle 2. (CONTINUED)

\begin{tabular}{|c|c|c|c|c|c|c|}
\hline \multirow[b]{2}{*}{ Test } & \multicolumn{2}{|c|}{ Mean } & \multicolumn{2}{|c|}{$S D$} & \multirow{2}{*}{$\begin{array}{c}\mathrm{t} \text {-test } \\
\mathrm{p} \text { value }\end{array}$} & \multirow{2}{*}{$\begin{array}{c}\text { MANOVA } \\
\text { p value }\end{array}$} \\
\hline & Control & $m T B I$ & Control & $m T B I$ & & \\
\hline Hyperactivity & 47.6 & 51.0 & 5.1 & 6.7 & 0.12 & \\
\hline ADHD index & 48.1 & 49.6 & 6.0 & 9.3 & 0.39 & \\
\hline \multicolumn{7}{|l|}{ CBCL (T-score) } \\
\hline Activities & 47.7 & 49.8 & 5.9 & 12.4 & 0.55 & \\
\hline Social & 48.6 & 54.3 & 8.3 & 8.7 & 0.032 & \\
\hline School & 53.1 & 50.6 & 3.7 & 7.6 & 0.34 & \\
\hline Total competence & 49.5 & 52.8 & 6.7 & 13.3 & 0.34 & \\
\hline Anxious/depressed & 53.3 & 54.5 & 5.5 & 6.7 & 0.65 & \\
\hline Withdrawn/depressed & 54.3 & 55.1 & 5.8 & 7.5 & 0.78 & \\
\hline Somatic complaints & 55.5 & 61.8 & 4.2 & 8.6 & 0.030 & \\
\hline Social problems & 53.1 & 54.9 & 4.7 & 5.9 & 0.26 & \\
\hline Thought problems & 52.9 & 55.9 & 4.3 & 6.6 & 0.23 & \\
\hline Attention problems & 52.7 & 53.8 & 3.5 & 4.9 & 0.48 & \\
\hline Rule-breaking behavior & 52.2 & 52.4 & 3.9 & 3.6 & 0.91 & \\
\hline Aggressive behavior & 53.3 & 52.4 & 5.4 & 3.3 & 0.66 & \\
\hline Internalizing problems & 50.2 & 55.2 & 9.2 & 9.9 & 0.25 & \\
\hline Externalizing problems & 48.4 & 48.1 & 8.6 & 7.0 & 0.93 & \\
\hline Total problems & 47.6 & 51.2 & 9.6 & 8.0 & 0.32 & \\
\hline \multicolumn{7}{|l|}{ CBCL DSM-IV } \\
\hline Affective problems & 54.7 & 55.3 & 7.3 & 7.1 & 0.82 & \\
\hline Anxiety problems & 53.8 & 53.7 & 6.4 & 5.5 & 0.97 & \\
\hline Somatic problems & 55.6 & 60.9 & 5.0 & 7.7 & 0.034 & \\
\hline ADH problems & 52.9 & 53.2 & 5.1 & 3.9 & 0.85 & \\
\hline Oppositional defiant problems & 54.7 & 52.6 & 4.9 & 2.6 & 0.19 & \\
\hline Conduct problems & 51.9 & 52.2 & 3.9 & 3.7 & 0.79 & \\
\hline
\end{tabular}

WASI, Wechsler Abbreviated Scale of Intelligence; RAVLT, Rey Auditory Verbal Learning Test; SDMT, Symbol Digit Modalities Test; PASAT, Paced Auditory Serial Addition Test; CPRS, Conners Rating Scale for Parents; CBCL, Child Behavior Checklist; DSM-IV, Diagnostic and Statistical Manual of Mental Disorders, 4th edition; [Beck Youth] BSCI, Beck Self-Concept Inventory; BAI, Beck Anxiety Inventory; BDI, Beck Depression Inventory; BANI, Beck Anger Inventory; BDBI, Beck Disruptive Behaviour Inventory; ADHD, attention deficit hyperactivity disorder; ADH, attention deficit hyperactivity; mTBI, mild traumatic injury; SD, standard deviation; MANOVA, multivariate analysis of variance.

associated control tasks, respectively. MANOVA results revealed that the mTBI group performed significantly worse than the control group across all accuracy conditions of the task, including verbal control $(F(1,28)=11.92, p=0.002)$, verbal working memory $(F(1,28)=10.79, p=0.003)$, nonverbal control $(F(1,28)=5.44$, $p=0.027)$, and nonverbal working memory $(F(1,28)=17.58$, $p<0.001)$. A subsequent MANOVA performed on the RT data did not reveal any significant group differences in speed of responding across the four conditions $(p>0.05)$.

\section{Functional neuroimaging data}

Working memory > control conditions. Independent sample $t$-tests compared the mean percentage of BOLD signal change for the verbal and nonverbal working memory conditions to their respective control conditions. Significant peak activations and $3 \mathrm{D} t$ maps depicting these activations can be found in Table 4 and Figure 2. Brain regions demonstrating greater bilateral activation for the verbal working memory versus control conditions included

Table 3. Functional Magnetic Resonance Imaging Experimental Task Data: Accuracy and Reaction Time for mTBI and Control Subjects

\begin{tabular}{|c|c|c|c|c|c|c|}
\hline & \multicolumn{2}{|c|}{ Mean } & \multicolumn{2}{|c|}{$S D$} & \multicolumn{2}{|c|}{$95 \%$ confidence interval } \\
\hline & $m T B I$ & Control & $m T B I$ & Control & $m T B I$ & Control \\
\hline \multicolumn{7}{|l|}{ Task condition } \\
\hline Verbal control ACC & 86.07 & 95.87 & 9.84 & 4.88 & $81.96-90.18$ & $91.76-99.98$ \\
\hline Verbal control RT & 1019.07 & 933.40 & 124.04 & 121.35 & $954.17-1083.96$ & $868.51-998.30$ \\
\hline Verbal WM ACC & 61.07 & 71.73 & 6.65 & 10.67 & $56.36-65.77$ & $67.03-76.44$ \\
\hline Verbal WM RT & 1233.60 & 1146.47 & 84.24 & 153.06 & $1168.26-1298.94$ & $1081.13-1211.81$ \\
\hline Nonverbal control ACC & 88.27 & 94.67 & 9.85 & 3.99 & 84.29-92.24 & 90.69-98.64 \\
\hline Nonverbal control RT & 967.73 & 912.33 & 120.65 & 97.16 & $909.80-1025.67$ & $854.40-970.27$ \\
\hline Nonverbal WM ACC & 61.53 & 74.93 & 7.41 & 9.91 & 56.91-66.16 & $70.31-79.56$ \\
\hline Nonverbal WM RT & 1181.20 & 1117.33 & 91.77 & 130.78 & $1121.45-1240.95$ & $1057.59-1177.08$ \\
\hline
\end{tabular}

mTBI, mild traumatic brain injury; WM, working memory; ACC, accuracy as percent correct; RT, reaction time in milliseconds; SD, standard deviation. 
Table 4. Functional Magnetic Resonance Imaging t-map Activation Peaks Unique to the Verbal and Nonverbal Working Memory Task Conditions Across All Subjects

\begin{tabular}{|c|c|c|c|c|c|c|c|c|c|}
\hline \multirow[b]{2}{*}{ Region } & \multirow[b]{2}{*}{$B A$} & \multicolumn{4}{|c|}{ Control } & \multicolumn{4}{|c|}{$m T B I$} \\
\hline & & $x$ & $y$ & $z$ & $t$ & $x$ & $y$ & $z$ & $t$ \\
\hline \multicolumn{10}{|c|}{ Verbal working memory condition activation peaks } \\
\hline Left dorsolateral prefrontal cortex & $9 / 46$ & -26 & 40 & 12 & 6.55 & - & - & - & - \\
\hline Left dorsolateral prefrontal cortex & 9 & -32 & 22 & 24 & 5.73 & -42 & 24 & 26 & 4.11 \\
\hline Right dorsolateral prefrontal cortex & $9 / 46$ & 32 & 48 & 16 & 6.18 & - & - & - & - \\
\hline Right dorsolateral prefrontal cortex & 9 & 48 & 26 & 34 & 5.82 & 40 & 30 & 28 & 4.23 \\
\hline Left rostral insula & & -30 & 20 & 2 & 7.59 & -30 & 22 & 2 & 4.32 \\
\hline Right rostral insula & & 30 & 22 & 0 & 7.50 & 34 & 22 & -2 & 4.13 \\
\hline Dorsal anterior cingulate cortex & 32 & 10 & 26 & 26 & 8.90 & 4 & 26 & 36 & 5.76 \\
\hline Supplementary motor area & & -4 & 4 & 58 & 7.34 & 8 & 14 & 48 & 5.29 \\
\hline Left premotor & 6 & -44 & -2 & 44 & 7.62 & -44 & 4 & 28 & 4.60 \\
\hline Right premotor & 6 & 34 & -2 & 50 & 5.21 & 38 & 2 & 30 & $3.73^{*}$ \\
\hline Left caudate nucleus & & -16 & -4 & 16 & 6.20 & -20 & -8 & 20 & $3.97 *$ \\
\hline Right caudate nucleus & & 16 & -2 & 14 & 4.61 & 18 & 2 & 20 & $3.39 *$ \\
\hline Left thalamus & & -12 & -14 & 10 & 6.21 & -12 & -12 & 6 & 4.11 \\
\hline Right thalamus & & 8 & -8 & 10 & 4.52 & 14 & -12 & 8 & $3.68 *$ \\
\hline Left superior temporal gyrus & 22 & -54 & -32 & 4 & 4.13 & -58 & -32 & -2 & $3.90 *$ \\
\hline Left superior parietal lobule & 7 & -28 & -64 & 54 & 6.58 & -36 & -40 & 34 & 4.98 \\
\hline Right superior parietal lobule & 7 & 42 & -46 & 48 & 5.15 & 40 & -46 & 40 & 4.96 \\
\hline Left inferior occipital gyrus & 19 & -40 & -68 & -4 & 6.16 & -38 & -66 & -10 & 4.87 \\
\hline Left inferior occipital gyrus & 18 & -24 & -96 & -6 & 5.51 & -26 & -92 & -6 & 4.61 \\
\hline Right inferior occipital gyrus & 18 & 34 & -86 & -2 & 6.49 & 26 & -94 & 2 & 4.78 \\
\hline \multicolumn{10}{|c|}{ Nonverbal working memory condition activation peaks } \\
\hline Left dorsolateral prefrontal cortex & $9 / 46$ & -26 & 42 & 12 & 5.12 & -30 & 50 & 12 & $3.18^{*}$ \\
\hline Left dorsolateral prefrontal cortex & 9 & -34 & 22 & 24 & 5.54 & - & - & - & - \\
\hline Right dorsolateral prefrontal cortex & 9 & 46 & 30 & 32 & 5.29 & 42 & 34 & 22 & $3.82 *$ \\
\hline Left rostral insula & & -30 & 22 & 4 & 8.04 & -30 & 20 & 4 & 5.15 \\
\hline Right rostral insula & & 30 & 22 & 2 & 9.69 & 32 & 22 & 4 & 4.88 \\
\hline Dorsal anterior cingulate cortex & 32 & 6 & 20 & 42 & 9.60 & 6 & 20 & 42 & 5.64 \\
\hline Supplementary motor area & & -6 & 4 & 56 & 7.54 & 8 & 14 & 48 & 6.02 \\
\hline Left premotor & 6 & -50 & -2 & 42 & 6.79 & -42 & 4 & 32 & 4.14 \\
\hline Right premotor & 6 & 34 & -2 & 50 & 5.66 & 34 & -4 & 52 & 4.43 \\
\hline Left caudate nucleus & & -18 & -2 & 18 & 5.84 & - & - & - & - \\
\hline Left thalamus & & -8 & -18 & 12 & 4.72 & - & - & - & - \\
\hline Right thalamus & & 6 & -14 & 14 & 5.54 & 8 & -20 & 14 & 4.51 \\
\hline Left superior parietal lobule & 7 & -28 & -62 & 50 & 6.86 & - & - & - & - \\
\hline Right superior parietal lobule & 7 & 28 & -62 & 52 & 4.93 & 32 & -70 & 34 & 4.55 \\
\hline Left fuiform gyrus & 37 & -34 & -54 & -14 & 6.74 & -36 & -50 & -18 & 5.96 \\
\hline Right fusiform gyrus & 37 & 36 & -50 & -18 & 6.11 & 30 & -50 & -18 & 4.91 \\
\hline Left inferior occipital gyrus & 19 & -40 & -76 & -8 & 7.51 & -38 & -74 & -14 & 4.66 \\
\hline Left inferior occipital gyrus & 18 & -30 & -86 & -6 & 6.86 & -42 & -90 & 0 & 4.77 \\
\hline Right inferior occipital gyrus & 19 & 32 & -72 & -14 & 6.43 & 36 & -76 & -10 & 4.19 \\
\hline Right inferior occipital gyrus & 18 & 40 & -80 & -6 & 6.52 & 44 & -78 & -2 & 6.79 \\
\hline Left primary visual cortex & 17 & -16 & -100 & 2 & 6.22 & -18 & -100 & -4 & $3.35^{*}$ \\
\hline Right primary visual cortex & 17 & 16 & -100 & 12 & 5.68 & 14 & -100 & 0 & 4.07 \\
\hline
\end{tabular}

$t$ threshold $=4.10, p<0.05$ corrected; *nonsignificant trend.

BA, Brodmann area; mTBI, mild traumatic brain injury.

the dorsolateral prefrontal cortex (Brodmann area [BA] 9/46, 46), premotor cortex (BA 6), superior parietal lobes (BA 7), inferior occipital cortices (BA 18, 19), insula, caudate nucleus, and thalamus. In addition, the supplementary motor area, left superior temporal gyrus, and dorsal anterior cingulate cortex (BA 32) also showed greater percent BOLD signal change for the verbal working memory versus control condition. The nonverbal working memory condition demonstrated greater percent BOLD signal change in all of the above areas as well as some additional regions. These were the bilateral fusiform gyrus (BA 37) and primary visual cortices (BA 17).
Control $>\mathrm{mTBI}$ participants. Independent sample $t$-tests comparing the mean percentage of BOLD signal change during the verbal working memory condition revealed significantly greater activation for the control versus the mTBI participants in the left (BA 9/46: $[t(2,28)=-5.59 ; p<0.001])$ and right dorsolateral prefrontal cortex (two activation peaks BA 9/46: $[t(2,28)=-5.10$; $p<0.001]$ and BA 9: $[t(2,28)=-3.92 ; p=0.001])$, left premotor cortex (BA: $6[t(2,28)=-3.34 ; p=0.002]$, supplementary motor area $[t(2,28)=-3.24 ; p=0.004]$, and left superior parietal lobule (BA 7: $[t(2,28)=-5.37 ; p<0.001]$; see Table 5; Fig. 3A). Of these regions, only the left dorsolateral prefrontal cortex (BA 9/46) was 


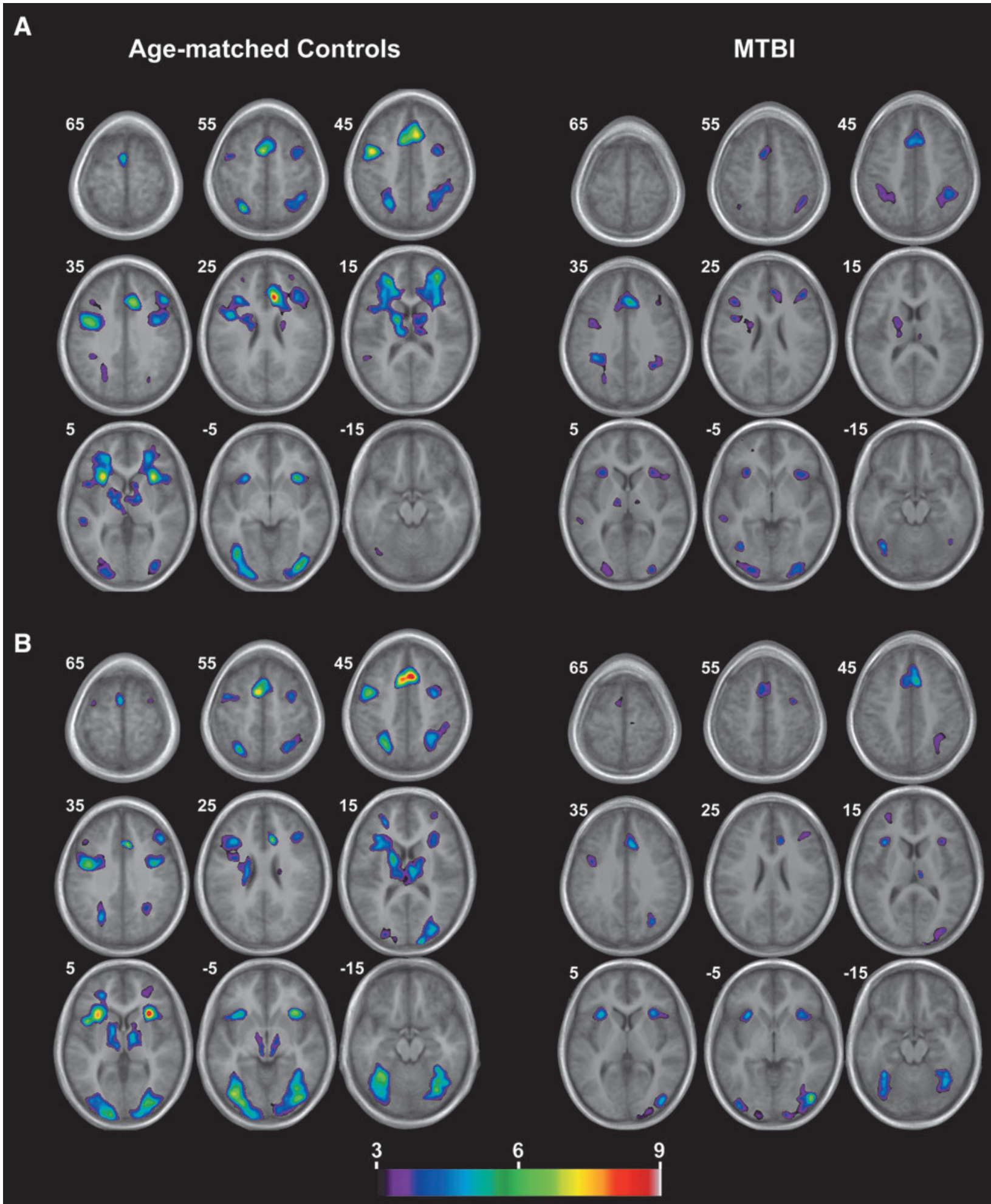

FIG. 2. Blood-oxygen-level-dependent activation patterns for (A) verbal and (B) nonverbal working memory condition against their respective control condition. The numbers correspond to the $\mathrm{z}$ coordinate, where the images were sampled. mTBI, mild traumatic brain injury. Color image is available at www.liebertpub.com/neu

found to be significantly correlated with performance such that greater activity in this region, relative to the verbal control condition, was significantly associated with greater accuracy for both the mTBI $(r=0.548 ; p=0.04)$ and control subjects $(r=0.699 ; p=0.04$; Fig. 4).
Independent sample $t$-tests comparing the mean percentage BOLD signal change revealed significantly greater activation for the control group versus the mTBI group in the left (BA 9: $[t$ (2, $28)=-5.95 ; p<0.001]$ and right $(\mathrm{BA} 9:[t(2,28)=-2.59$; $p=0.015$ ] dorsolateral prefrontal cortex as well as the dorsal 
Table 5. Functional Magnetic Resonance Imaging t-map Activation Peaks for Control > mTBI Participants

\begin{tabular}{|c|c|c|c|c|c|}
\hline region & $B A$ & $x$ & $y$ & $z$ & $t$ \\
\hline \multicolumn{6}{|l|}{ Verbal working memory } \\
\hline Left dorsolateral prefrontal cortex & $9 / 46$ & -42 & 40 & 12 & 3.00 \\
\hline Right dorsolateral prefrontal cortex & $9 / 46$ & 32 & 42 & 16 & 3.45 \\
\hline Right dorsolateral prefrontal cortex & 9 & 48 & 26 & 28 & 3.28 \\
\hline Left premotor cortex & 6 & -46 & -2 & 44 & 4.76 \\
\hline Supplementary motor area & & -2 & 4 & 56 & 3.60 \\
\hline Left superior parietal lobule & 7 & -22 & -66 & 50 & 3.74 \\
\hline \multicolumn{6}{|l|}{ Nonverbal working memory } \\
\hline Left dorsolateral prefrontal cortex & 9 & -32 & 22 & 24 & 3.00 \\
\hline Right dorsolateral prefrontal cortex & 9 & 42 & 26 & 28 & 2.70 \\
\hline Dorsal anterior cingulate cortex & 32 & 4 & 18 & 42 & 3.56 \\
\hline Left premotor cortex & & -48 & -4 & 44 & 4.37 \\
\hline Supplementary motor area & & -6 & 4 & 54 & 3.92 \\
\hline Left superior parietal lobule & 7 & -22 & -68 & 50 & 3.74 \\
\hline Left caudate nucleus & & -18 & -2 & 20 & 3.07 \\
\hline Left Thalamus & & -4 & -16 & 6 & 2.93 \\
\hline
\end{tabular}

mTBI, mild traumatic brain injury; BA, Brodmann area.

anterior cingulate cortex (BA 32: $[t(2,28)=-3.56 ; p=0.001]$, left premotor cortex (BA 6: $[t(2,28)=-3.16 ; p=0.004]$, supplementary motor area $[t(2,28)=-3.44 ; p=0.003]$, left superior parietal lobe (BA 7: $[t(2,28)=-3.23 ; p<0.003]$, left thalamus $[t(2$, $28)=-2.54 ; p=0.017]$, and left caudate nucleus $[t(2,28)=-4.88$; $p<0.001]$ during the nonverbal working memory condition (see Table 5; Fig. 3B). Of these regions, the left $(r=0.808 ; p<0.001)$ and right $(r=0.895 ; p<0.001)$ dorsolateral prefrontal cortices were found to be significantly correlated with performance for the mTBI subjects only (Fig. 4).

The reverse analysis (mTBI > control) did not reveal any significant regions of greater percent BOLD signal change for the mTBI participants on either the verbal or nonverbal working memory tasks.

\section{Discussion}

The aim of this study was to examine and compare working memory performance and related brain activity using fMRI in concussed youths and healthy age-matched control subjects. As hypothesized, the behavioral data revealed significant group differences in performance, where the concussed subjects demonstrated significantly poorer accuracy on both the verbal and visual versions of the task, with no difference in reaction time. However, concussed subjects also demonstrated significantly poorer performance on the baseline condition of each task. This finding is different from previous studies examining working memory performance in concussed versus control adult subjects, where no difference in group performance had been found. ${ }^{20,21,23}$ However, these findings are similar to other studies that document decreased performance on working memory tasks after more-severe TBI in children, ${ }^{32,33}$ and they suggest that attentional and/or more general associative learning deficits specific to the baseline task may be present as well, given the poorer performance on the baseline task. Neuropsychological findings that demonstrated statistically significant differences in performance between the mTBI and control groups (RAVLT Delayed Memory Recall and Verbal Fluency) also suggest the presence of more-general learning challenges in this group. These findings support previous studies suggesting that the adolescent group may be more vulnerable to the neuropsychological effects of sports concussion than younger children or adults. ${ }^{13}$
PCS scores were also significantly different between the concussed and control groups, indicating that some members of the concussed group were still clinically symptomatic. Therefore, it is unknown whether these group differences in cognitive performance would persist or resolve with symptom resolution.

This study is unique and the first of its kind to link behavioral deficits in working memory performance after concussion in youth with functional alterations in brain activity. In one of the few previous investigations involving youth athletes, ${ }^{28} \mathrm{fMRI}$ activation patterns in concussed athletes shifted from greater activity during the more-complex task to greater activity during the less-complex task, suggesting hyperactivation associated with the simpler task condition. ${ }^{30}$ However, the researchers did not report on whether there were performance differences between groups on the tasks. Similarly, whereas Yang and colleagues ${ }^{30}$ found hypoactivation during an auditory orienting task in mTBI youths, relative to healthy controls, this difference did not correlate with task performance and there were no statistically significant differences between the groups in this respect.

Overall, in the present study, similar regions were associated with BOLD signal change for both the verbal and nonverbal abstract design conditions across concussed and age-matched control subjects. Regions demonstrating BOLD signal change included bilateral prefrontal, premotor, parietal, and occipital cortices as well as the dorsal anterior cingulate cortex. A direct comparison of percent BOLD change from the baseline task to the verbal working memory task revealed significantly greater change for the controls, compared to the concussed subjects, in the left premotor cortex. The same analysis with the nonverbal abstract design condition also revealed greater percent BOLD change in the left premotor cortex for agematched control subjects, as well as greater change in the left dorsolateral prefrontal and dorsal anterior cingulate cortices. The reverse analysis did not reveal any regions where concussed subjects showed greater percent BOLD signal change from baseline to working memory task condition, compared to age-matched control subjects.

Given its demonstrated importance for working memory and the observed difference in performance for concussed versus control subjects, we regressed percent change in BOLD signal in this region on working memory performance and found a significant relationship between the two in the left and right hemispheres for the 

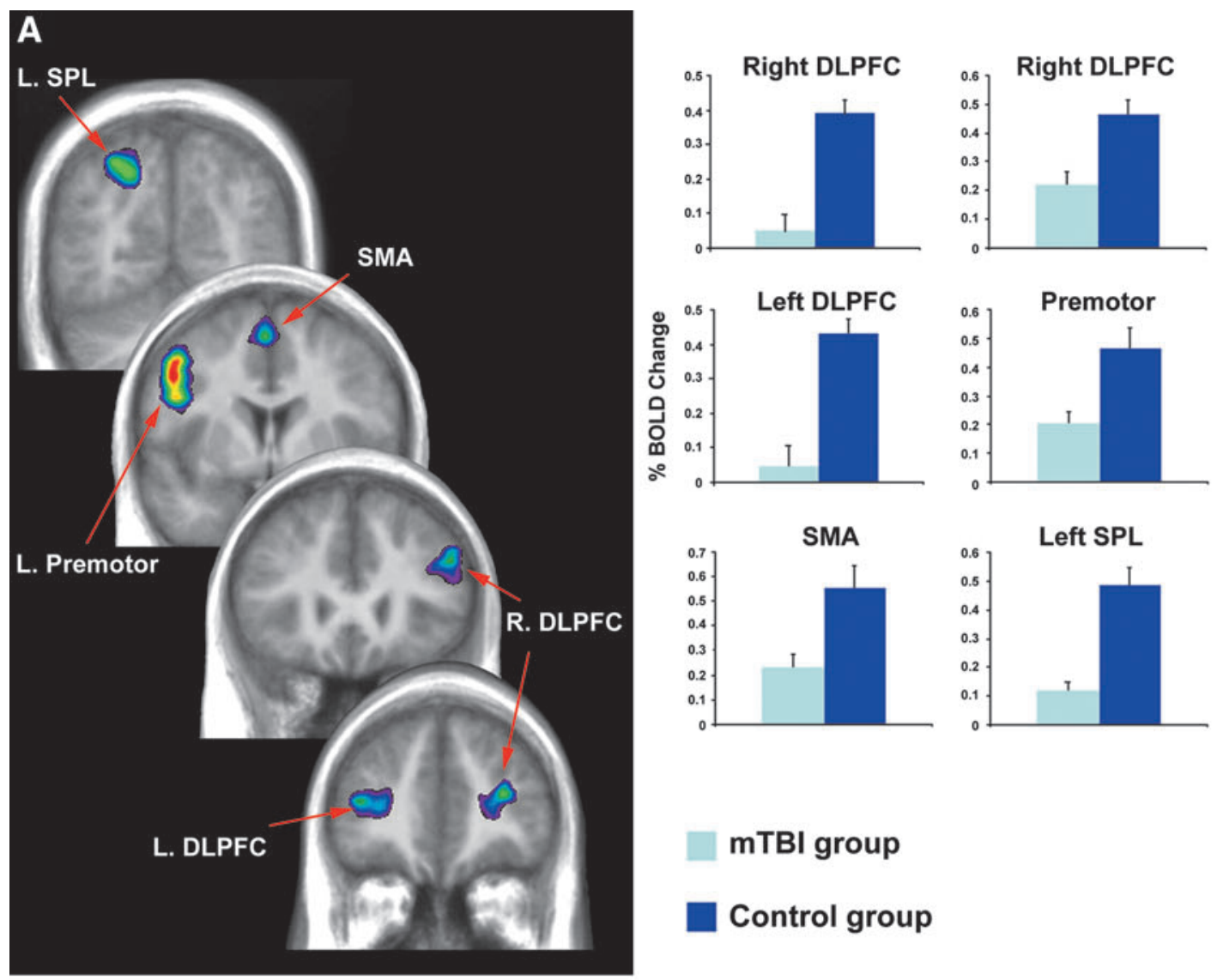

\section{mTBI group}

Control group
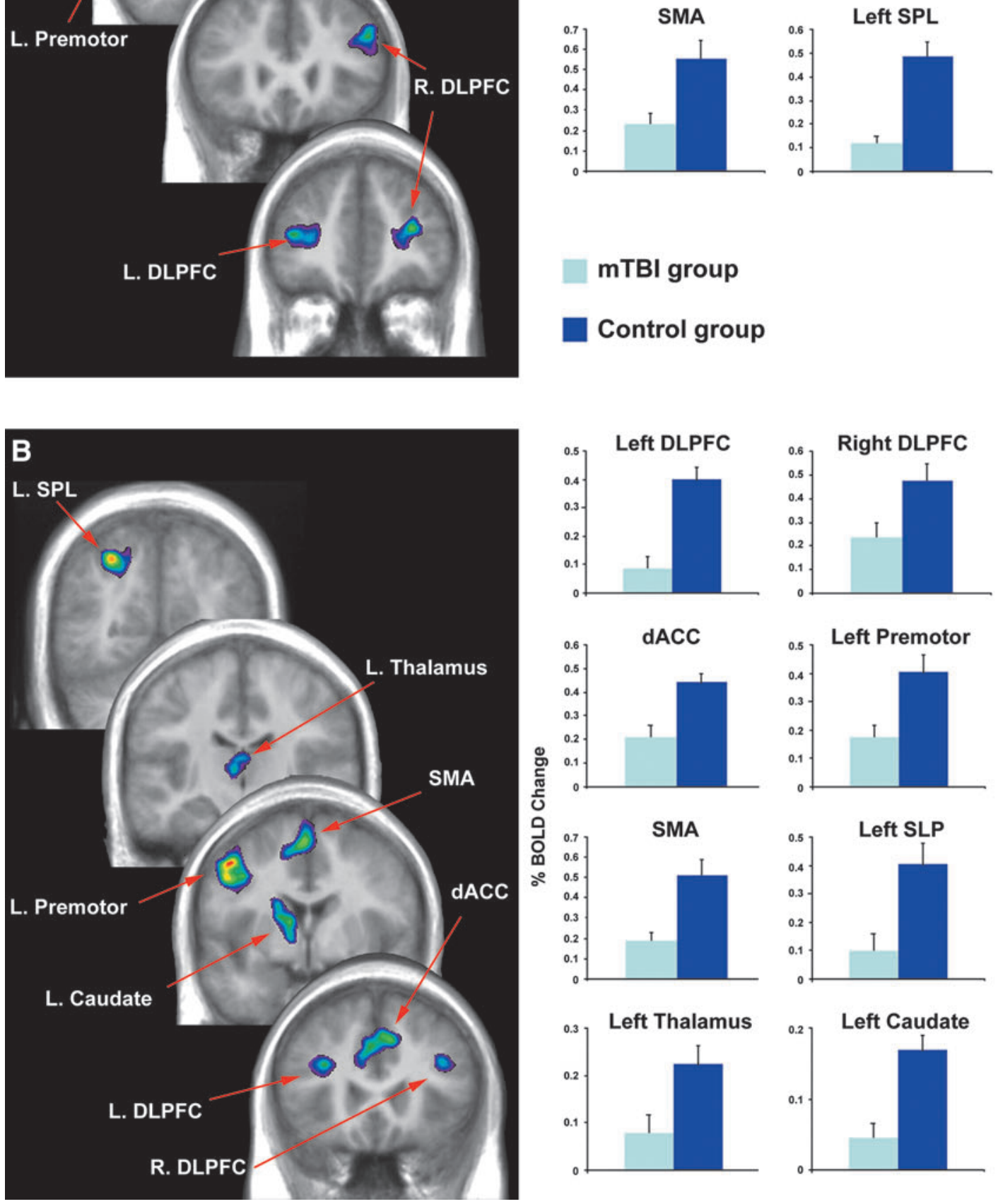

FIG. 3. Results from between-group subtraction showing significantly greater activation for control versus mTBI participants during the (A) verbal and (B) nonverbal working memory condition. mTBI, mild traumatic brain injury; BOLD, blood-oxygen-level dependent; DLPFC, dorsolateral prefrontal cortex; SPL, superior parietal lobule; SMA, supplementary motor area; dACC, dorsal anterior cingulate cortex. Color image is available at www.liebertpub.com/neu 


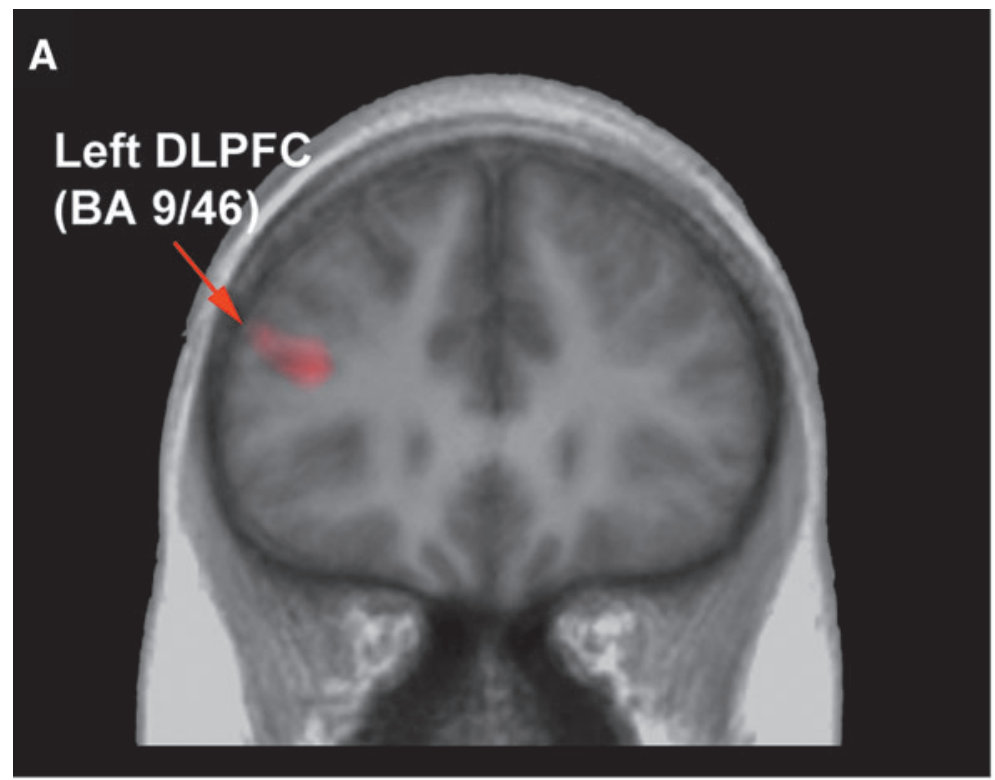

Left DLPFC (BA 9/46)

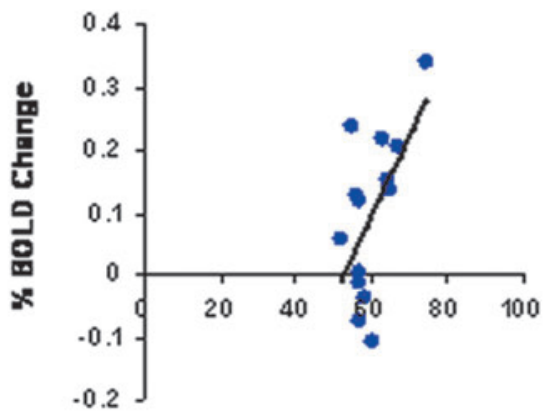

Performance ( $\%$ correct)
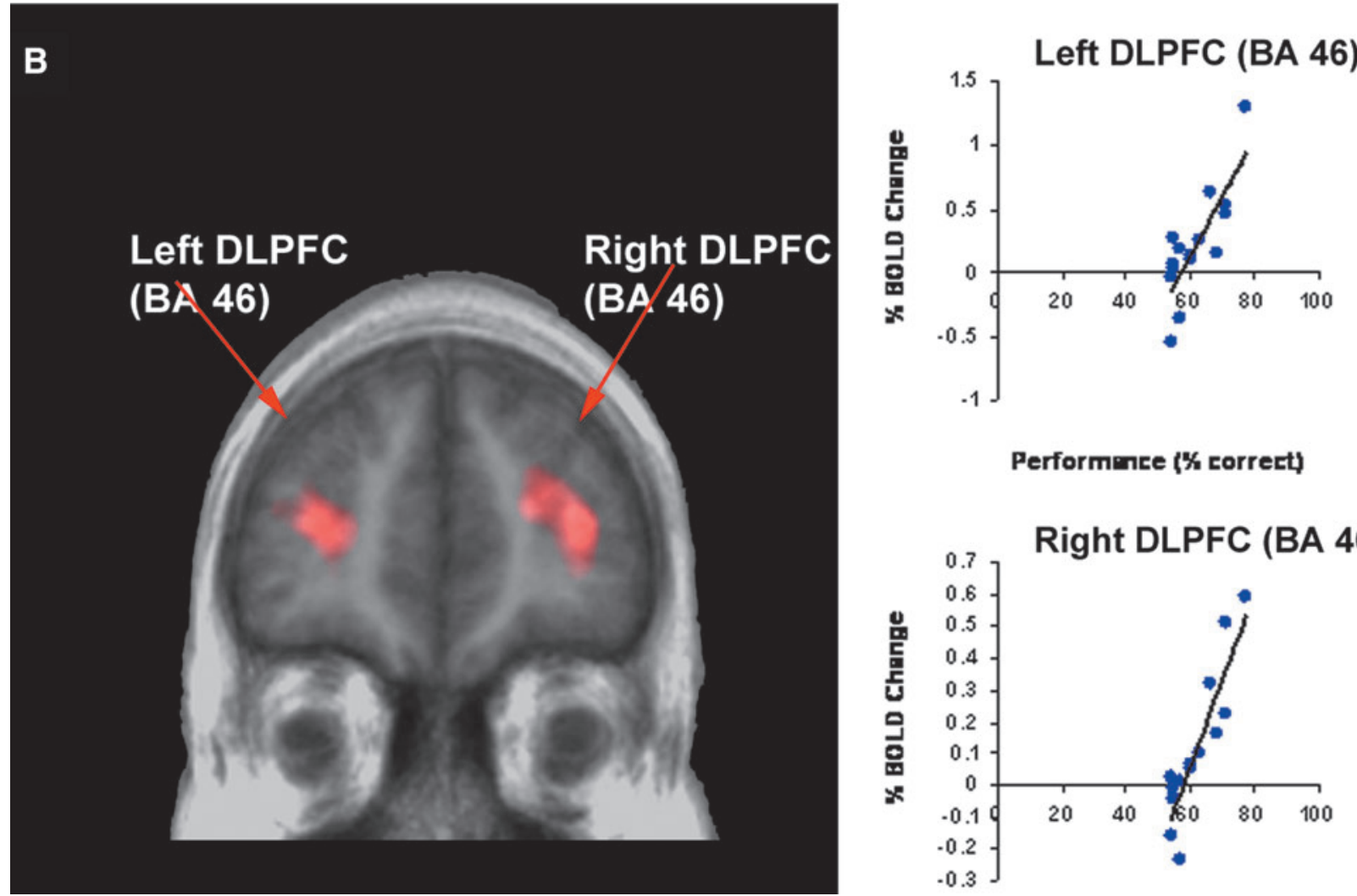

Performance (K) correct)

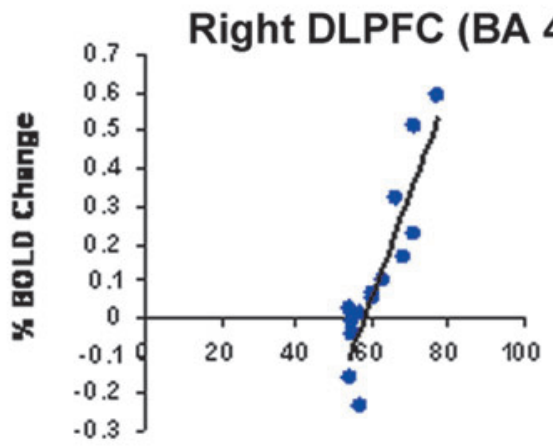

FIG. 4. Whole-brain regression analysis showing brain areas of the concussed group where BOLD signal changes were modulated by performance accuracy for $(\mathbf{A})$ verbal and $(\mathbf{B})$ nonverbal working memory. BOLD, blood-oxygen-level dependent; DLPFC, dorsolateral prefrontal cortex; BA, Brodmann area. Color image is available at www.liebertpub.com/neu

nonverbal visual abstract design condition as well as a trend toward significance for the verbal condition. Interestingly, performance was not correlated with PCS severity, suggesting that performance may be directly related to the lack of BOLD signal change in this region and not solely as a result of the presence of somatic and cognitive PCS, such as headache, fatigue, and so on. This is an important finding, given that return-to-play decisions are made based solely on the absence of PCS.
Taken together, these results suggest that, unlike in adults, working memory performance in youth is significantly affected by concussion. Moreover, unlike the adult population, where differences in performance are not observed between mTBI subjects and healthy controls, ${ }^{18,20,21,23}$ there is a significant relationship between activity in this region and performance in youth, suggesting poorer compensatory resources after mTBI in the immature brain. 
These results cannot be solely explained by differences in task methodology, because we deliberately employed the same experimental paradigm used by Chen and colleagues ${ }^{20,21}$ in order to compare our findings to adult subjects. In addition to lack of BOLD signal change found in the dorsolateral prefrontal cortex, Chen and colleagues $^{20,21}$ also reported regions of increased BOLD signal change in the temporal lobes of concussed adults while performing the nonverbal abstract design working memory task. The reason for this pattern of findings is unclear. Regions of hyperactivation have been suggested in many areas of neuroimaging investigation to reflect compensatory strategies in information processing. In the current study, we did not find any regions of hyperactivation during either the verbal or nonverbal visual abstract design condition, supporting the idea that youths may be less likely to engage compensatory mechanisms to maintain cognitive performance after a mild neural insult.

Further research is clearly needed to better understand the relationship observed between changes in working memory performance and cortical activity. The lack of ability to engage compensatory mechanisms is one possible hypothesis. Specific underlying neural mechanisms may be related to pathophysiological differences in the immature brain, which make it more vulnerable to neuronal injury. These pathophysiological differences include the mechanical and compositional properties of the brain, which result in a markedly diminished shear resistance of immature brain tissue. ${ }^{7}$ As such, immature brain tissue appears to be more susceptible to mechanical alterations, because similar mechanical loads induce a more intense brain tissue displacement. Although our concussed athletes were not young children (the mean age was 14 years for both groups), the frontal lobes demonstrate protracted structural development, compared to other regions in the brain, and thus continue to develop throughout adolescence and into adulthood. ${ }^{56}$ This protracted development has been shown to be related to the ability to perform demanding memory tasks. ${ }^{56}$ More specifically, Crone and colleagues ${ }^{27}$ focused on development of nonspatial working memory and revealed that although children made more errors than adolescents and adults, they engaged highly overlapping brain regions during task performance. A significant positive correlation was found between accuracy and activation in the dorsolateral prefrontal cortex. This region has demonstrated particular involvement for the manipulation of items in working memory in adolescents and adults, ${ }^{57}$ but not in 8 - to 12 -year-olds. ${ }^{27}$

\section{Clinical implications}

The findings from this study regarding poorer cognitive performance associated with differential patterns of cortical activation after youth concussion supports the 4th International Consensus Statement, which advises greater caution in the clinical management of youths after sports-related concussion. ${ }^{58}$ This statement, which represents the clinical "gold standard" for concussion management, highlights the need to consider the developmental impact of concussive injuries, such as diffuse cerebral swelling, and to increase rest and recovery time after injury, accordingly. The statement additionally highlights the need for cognitive rest that includes school and recreational activities, such as video games and text messaging. The results from the current study provide the first known empirical data to support this recommendation for concussed youth, and further research is clearly indicated to better understand the nature of working memory performance deficits and associated alterations in corti- cal activity. The impact of concussion on short-term cognitive function has serious implications for the risk of reinjury and second impact syndrome (where the brain swells rapidly and catastrophically if a second injury is incurred before complete neuronal recovery from an earlier injury) if youth athletes return to sport participation too early. Overall, there is a dire need for systematic evaluation and reintegration after concussion in youth. The results of the regression analysis validate the idea that fMRI activity in well-studied regions of interest (e.g., the dorsolateral prefrontal cortex) hold significant potential as clinical markers of recovery in youth as well as adults.

\section{Methodological considerations}

The employment of a subtraction technique in the current study does not allow us to determine whether the lack of change in BOLD signal is the result of decreased activity for both baseline and working memory task or hyperactivation for baseline task in mTBI group. This is important to consider because some studies have shown hyperactivation after concussion in youth athletes. ${ }^{28,31} \mathrm{Fi}-$ nally, in the current study, concussed participants were still symptomatic (mean PCS score, 31; SD, 18), so not representative of uncomplicated concussion where youth may recover quickly (i.e., 7-10 days after injury).

\section{Conclusions}

Functional alterations in brain activity during a working memory task show some similarity between youth and adults, including a lack of BOLD signal change in the dorsolateral prefrontal cortex. However, there are also notable and significant differences. In particular, the observation of reduced working memory accuracy, relative to healthy controls, is of great concern and warrants further investigation. Combined with a lack of increased BOLD signal typically observed in temporal and parietal regions, ${ }^{20,21,31}$ it suggests that youths may be unable to engage compensatory strategies to maintain cognitive performance after neuronal injury. This has significant implications for safe return to daily activities, including competitive sport.

\section{Acknowledgments}

The authors thank CIHR (grant no. 484706; primary investigator: M. Keightley; coinvestigators: A. Ptito, K. Johnston, and N. Lobaugh) for their financial support of this study as well as the members of the Trauma Program of the Montreal Children's Hospital, McGill University Health Center, for their collaboration.

\section{Author Disclosure Statement}

No competing financial interests exist.

\section{References}

1. Browne, G.J., and Lam, L.T. (2006). Concussive head injury in children and adolescents related to sports and other leisure physical activities. Br. J. Sports Med. 40, 163-168.

2. McCrory, P., Collie, A., Anderson, V., and Davis, G. (2004). Can we manage sport related concussion in children the same as in adults? Br. J. Sports Med. 38, 516-519.

3. McCrory, P., Meeuwisse, W., Johnston, K., Dvořák, J., Aubry, M., Molloy, M., and Cantu, R. (2009). Consensus statement on concussion in sport-the 3rd International Conference on Concussion in Sport held in Zurich, November 2008. Clin. J. Sport Med. 19, 185-200.

4. Goldstrohm, S.L., and Arffa, S. (2005). Preschool children with mild to moderate traumatic brain injury: an exploration of immediate and post-acute morbidity. Arch. Clin. Neuropsychol. 20, 675-695. 
5. Satz, P. (1993). Brain reserve capacity on symptom onset after brain injury: a formulation and review of evidence for threshold theory. Neuropsychology 7, 273-295.

6. Kirkwood, M.W., Yeates, K.O., and Wilson, P.E. (2006). Pediatric sport-related concussion: a review of the clinical management of an oft-neglected population. Pediatrics 117, 1359-1371.

7. Bauer, R., and Fritz, H. (2004). Pathophysiology of traumatic injury in the developing brain: an introduction and short update. Exp. Toxicol. Pathol. 56, 65-73.

8. Freund, J., Hayter, C., MacDonald, S., Neary, M., and WisemanHakes, C. (1994) Cognitive-Communication Disorders Following Traumatic Brain Injury, 1st ed. Communication Skillbuilders Inc.: Austin, TX.

9. Wiseman-Hakes, C., Spiegler, B., and Collings, A. (2000). Later developmental impact of pediatric frontal lobe injury: a case study. Poster presentation at The Frontal Lobes: Rotman Research Institute, Toronto, Ontario, Canada, 2000.

10. Lovell, M.R., Collins, M.W., Iverson, G.L., Field, M., Maroon, J.C., Cantu, R., Podell, K., Powell, J.W., Belza, M., and Fu, F.H. (2003). Recovery from mild concussion in high school athletes. J. Neurosurg. 98, 296-301

11. McCrea, M., Guskiewicz, K.M., Marshall, S.W., Barr, W., Randolph, C., Cantu, R.C., Onate, J.A., Yang, J., and Kelly, J.P., (2003). Acute effects and recovery time following concussion in collegiate football players: the NCAA Concussion Study. JAMA 290, 2556-2563.

12. Gagnon, I., Galli, C., Friedman, D., Grilli, L., and Iverson, G.L. (2009). Active rehabilitation for children who are slow to recover following sport-related concussion. Brain Inj. 23, 956-964.

13. Baillargeon, A., Lassonde, M., Leclerc, S., and Ellemberg, D. (2012). Neuropsychological and neurophysiological assessment of sport concussion in children, adolescents and adults. Brain Inj. 26, 211-220.

14. Doezema, D., King, J.N., Tandberg, D., Espinosa, M.C., and Orrison, W.W. (1991). Magnetic resonance imaging in minor head injury. Ann. Emerg. Med. 20, 1281-1285.

15. Mittl, R.L., Grossman, R.I., Hiehle, J.F., Hurst, R.W., Kauder, D.R., Gennarelli, T.A., and Alburger, G.W. (1994). Prevalence of MR evidence of diffuse axonal injury in patients with mild head injury and normal head CT findings. AJNR Am. J. Neuroradiol. 15, 15831589.

16. Hughes, D.G., Jackson, A., Mason, D.L., Berry, E., Hollis, S., and Yates, D.W. (2004). Abnormalities on magnetic resonance imaging seen acutely following mild traumatic brain injury: Correlation with neuropsychological tests and delayed recovery. Neuroradiology 46, $550-558$.

17. Gale, S.D., Baxter, L., Roundy, N., and Johnson, S.C. (2005). Traumatic brain injury and grey matter concentration: a preliminary voxel based morphometry study. J. Neurol. Neurosurg. Psychiatry 76, 984-988.

18. McAllister, T.W., Saykin, A.J., Flashman, L.A., Sparling, M.B., Johnson, S.C., Guerin, S.J., Mamourian, A.C., Weaver, J.B., and Yanofsky, N. (1999). Brain activation during working memory 1 month after mild traumatic brain injury: a functional MRI study. Neurology 53, 1300-1308.

19. McAllister, T.W., Sparling, M.B., Flashman, L.A., Guerin, S.J., Mamourian, A.C., and Saykin, A.J. (2001). Differential working memory load effects after mild traumatic brain injury. Neuroimage 14, 1004 1012.

20. Chen, J.K., Johnston, K.M., Frey, S., Petrides, M., Worsley, K., and Ptito, A. (2004). Functional abnormalities in symptomatic concussed athletes: an fMRI study. Neuroimage 22, 68-82.

21. Chen, J.K., Johnston, K.M., Collie, A., McCrory, P., and Ptito, A. (2007). A validation of the post concussion symptom scale in the assessment of complex concussion using cognitive testing and functional MRI. J. Neurol. Neurosurg. Psychiatry 78, 1231-1238.

22. Jantzen, K.J., Anderson, B., Steinberg, F.L., and Kelso, J.A. (2004). A prospective functional MR imaging study of mild traumatic brain injury in college football players. AJNR Am. J. Neuroradiol. 25, 738745 .

23. Pardini, J.E., Becker, J.T., Dunfee, K.L., Eddy, W.F., Lovell, M.R., and Welling, J.S. (2010). Postconcussive symptoms are associated with compensatory cortical recruitment during a working memory task. Neurosurgery 67, 1020-1028.

24. Keightley, M.L., Chen, J.K., and Ptito, A. (2012). Examining the neural impact of pediatric concussion: a scoping review of multimodal and integrative approaches using functional and structural MRI techniques. Curr. Opin. Pediatr. 24, 709-716.
25. Cantu, R.C. (1998). Return to play guidelines after a head injury. Clin J. Sports Med. 17, 45-60.

26. Nagel, B.J., Barlett, V.C., Schweinsburg, A.D., and Tapert, S.F. (2005). Neuropsychological predictors of BOLD response during a spatial working memory task in adolescents: what can performance tell us about fMRI response patterns? J. Clin. Exp. Neuropsychol. 27, 823-839.

27. Crone, E.A., Wendelken, C., Donohue, S., van Leijenhorst, L., and Bunge, S.A. (2006). Neurocognitive development of the ability to manipulate information in working memory. Proc. Natl. Acad. Sci. U. S. A. 103, 9315-9320.

28. Talavage, T.M., Nauman, E., Breedlove, E.L., Yoruk, U., Dye, A.E., Morigaki, K., Feuer, H., and Leverenz, L.J. (2013). Functionally-detected cognitive impairment in high school football players without clinically-diagnosed concussion. J. Neurotrauma Apr 11. doi: 10.1089/ neu.2010.1512.

29. Maugans, T.A., Farley, C., Altaye, M., Leach, J., and Cecil, K.M. (2012). Pediatric sports-related concussion produces cerebral blood flow alterations. Pediatrics 129, 28-37.

30. Yang, Z., Yeo, R.A., Pena, A., Ling, J.M., Klimaj, S., Campbell, R., Doezema, D., and Mayer, A.R. (2012). An fMRI study of auditory orienting and inhibition of return in pediatric mild traumatic brain injury. J. Neurotrauma 29, 2124-2136.

31. Lovell, M., Pardini, J., Welling, J., Collins, M., Bakal, J., Lazar, N., Roush, R., Eddy, W.F., and Becker, J.T. (2007). Functional brain abnormalities are related to clinical recovery and time to return-toplay in athletes. Neurosurgery 61, 352-359.

32. Levin, H.S., Hanten, G., Zhang, L., Swank, P.R., Ewing-Cobbs, L., Dennis, M., Barnes, M.A., Max, J., Schachar, R., Chapman, S.B., and Hunter, J.V. (2004). Changes in working memory after traumatic brain injury in children. Neuropsychology 18, 240-247.

33. Moran, C., and Gillon, G. (2004). Language and memory profiles of adolescents with traumatic brain injury. Brain Inj. 18, 273-88.

34. McAllister, T.W., Sparling, M.B., Flashman, L.A., and Saykin, A.J. (2001). Neuroimaging findings in mild traumatic brain injury. J. Clin. Exp. Neuropsychol. 23, 775-791.

35. Ciesielski, K.T., Lesnik, P.G., Savoy, R.L., Grant, E.P., and Ahlfors, S.P. (2006). Developmental neural networks in children performing a categorical N-back task. Neuroimage 33, 980-990.

36. Cassidy, J.D., Carroll, L.J., Peloso, P.M., Borg, J., von Holst, H., Holm, L., Kraus, J., and Coronado, V.G. (2004). Incidence, risk factors and prevention of mild traumatic brain injury: results of the WHO collaborating centre task force on mild traumatic brain injury. J. Rehabil. Med. 43, 28-60.

37. Waschbusch, A., and Willoughby, M.T. (2008). Parent and teacher ratings on the IOWA Conners Rating Scale. J. Psychopathol. Behav. Assess. 30, 180-192.

38. Lovell, M.R., and Collins, M.W. (1998). Neuropsychological assessment of the college football player. J. Head Trauma Rehabil. 139, 2626.

39. Wechsler, D. (1999). Wechsler Abbreviated Scale of Intelligence (WASI). The Psychological Corporation: San Antonio, TX.

40. Meyers, J.E., and Meyers, K.R. (1995). Rey Complex Figure and Recognition Trial: professional manual. Psychological Assessment Resources: Odessa, FL.

41. Miller, E. (1984). Verbal fluency as a function of a measure of verbal intelligence and in relation to different types of cerebral pathology. $\mathrm{Br}$. J. Clin. Psychol. 25, 53-57.

42. Lezak, M.D., Howieson, D.B., and Loring, D.W. (2004). Neuropsychological Assessment, 4th ed. Oxford University Press: New York.

43. Golden, C.J. (1978). The Stroop Color and Word Test: a manual for clinical and experimental uses. Stoelting: Chicago, IL.

44. Smith, A. (1968). The symbol-digit modalities test: a neuropsychologic test of learning and other cerebral disorders, in: Learning Disorders. J. Helmuth (ed). Special Child Publications: Seattle, WA, pps. 83-91.

45. Williams, J., Rickert, V., Hogan, J., Zolten, A.J., Satz, P., D’Elia, L.F., Asarnow, R.F., Zaucha, K., and Light, R. (1995). Children's color trails. Arch. Clin. Neuropsychol. 10, 211-223.

46. Bryden, P.J., and Roy, E.A. (2005). A new method of administering the Grooved Pegboard Test: performance as a function of handedness and sex. Brain Cogn. 58, 258-268.

47. Achenbach, T.M., and Edelbrook, C. (1983). Manual for the Child Behaviour Checklist and Revised Behaviour Profile. University of Vermont: Burlington, VT. 
48. Beck, J.S., Beck, A.T., Jolly, J.B., and Steer, R.A. (2005). Beck Youth Inventories-Second Edition for Children and Adolescents manual. PsychCorp: San Antonio, TX.

49. Petrides, M., Frey, S., and Chen, J.K. (2001). Increased activation of the mid-dorsolateral frontal cortex during the monitoring of abstract visual and verbal stimuli. Proceedings of 7 th International Conference of Functional Mapping of Human Brain, Brighton, UK, 2001. Neuroimage $13, \mathrm{~S} 721$.

50. Petrides, M., Alivisatos, B., Meyer, E., and Evans, A.C. (1993). Functional activation of the human frontal cortex during the performance of verbal working memory tasks. Proc. Natl. Acad. Sci. U. S. A. $90,878-882$.

51. Stern, C.E., Owen, A.M., Tracey, I., Look, R.B., Rosen, B.R., and Petrides, M. (2000). Activity in ventrolateral and mid-dorsolateral prefrontal cortex during nonspatial visual working memory processing: evidence from functional magnetic resonance imaging. NeuroImage 11, 392-399.

52. Worsley, K.J., Liao, C.H., Aston, J., Petre, V., Duncan, G.H., Morales, F., and Evans, A.C. (2002). A general statistical analysis for fMRI data. Neuroimage 15, 1-15.

53. Friston, K.J., Fletcher, P., Josephs, O., Holmes, A., Rugg, M.D., and Turner, R. (1998). Event-related fMRI: characterizing differential responses. Neuroimage 7, 30-40.

54. Collins, D.L., Neelin, P., Peters, T.M., and Evans, A.C. (1994). Automatic 3D inter-subject registration of MR volumetric data in standardized talairach space. J. Comput. Assist. Tomogr. 18, 192-205.
55. Worsley, K.J. (2005). Spatial smoothing of autocorrelations to control the degrees of freedom in fMRI analysis. Neuroimage 26, 635-641.

56. Romine, C.B., and Reynolds, C.R. (2004). Sequential memory: a developmental perspective on its relation to frontal lobe functioning. Neuropsychol. Rev. 14, 43-64.

57. Wager, T.D., and Smith, E.E. (2003). Neuroimaging studies of working memory: a meta-analysis. Cogn. Affect. Behav. Neurosci. 3, 255-274.

58. McCrory, P., Meeuwisse, W.H., Aubry, M., Cantu, B., Dvořák, J., Echemendia, R.J., Engebretsen, L., Johnston, K., Kutcher, J., Raftery, M., Sills, A., Benson, B., Davis, G., Ellenbogen, R., Guskiewicz, K., Herring, S.A., Iverson, G., Jordan, B., Kissick, J., McCrea, M., McIntosh, A., Maddocks, D., Makdissi, M., Purcell, L., Putukian, M., Schneider, K., Tator, C., and Turner, M. (2013). Consensus statement on concussion in sport: the 4th International Conference on Concussion in Sport held in Zurich, November 2012. Br. J. Sports Med. 47, 250-258.

Address correspondence to:

Michelle L. Keightley, PhD

Bloorview Research Institute

Holland Bloorview Kids Rehabilitation Hospital

150 Kilgour Road

Toronto, Ontario, Canada M4G $1 R 8$

E-mail: mkeightley@hollandbloorview.ca 